\title{
Building Resilient and Meaningful Enterprises with the Sustainability Lens
}

\author{
Tamara L. Stenn \\ Landmark College
}

The Sustainability Lens is a paradigm that combines indigenous knowledge, permaculture, solidarity economy and Circles of Sustainability into a four-quadrant tool that works with the Business Model Canvas to build more fun and sustainable solutions into every aspect of one's enterprise - from start-ups to seasoned industry. It highlights the supply chain, human resource function, product development, marketing and customer relations and compliments approaches such as Lean Launchpad for innovation and Blue Ocean Canvas for value creation.

\section{INTRODUCTION}

The Business Model Canvas (BMC), downloaded over 5 million times and used by thousands of corporations and startups worldwide, opens a new, agile way in which to imagine and develop a company (Amarsy, 2015). Users report the BMC's greatest strengths are its ability to create better conversations on strategy, a shared language and the new ideas it generates. Fifty-seven percent of the time, the BMC is used for new business and product development (ibid).

At the same time, there has been a paradigm shift in global sustainability awareness with communities and individuals exerting pressure on many corporations, government agencies, non-profit organizations and households to be more ethically and environmentally minded in their day-to-day activities (Cohen, 2014). There are now greater demands for transparency, environmental conservation, green supply chains, renewable energy, recycling, economic justice, and social returns such as community building and new opportunities for disadvantaged populations - linked to products and services. It is no longer enough just to produce a decent product. Information about how products are made and their environmental and social impacts are easy to share as technology exposes businesses to much more scrutiny and creates opportunities to form closer customer relations.

Sustainability can be defined as a long-term balance between consumers and resources that is not harmful to others or depletes the natural environment. When paired with development, sustainability becomes more complex - a dynamic with a push towards controlled growth. Overall, Sustainable Development is an intentional, closed loop model where inputs and outputs are balanced and materials are transformed and re-used in self-perpetuating ways. Sustainability can be understood in the natural world when complex, symbiotic relationships form around the transformation of matter for the benefit and development of all.

Businesses are well positioned to enter into a new era of self-initiated, sustainable development and corporate responsibility - driven by consumer demand and their agility and independence in decision making. Leading industrialists argue that not only is sustainable development good for business, the 
solving of environmental and social problems is essential for the future of the planet. Charles Holliday Jr. and Philip Watts, leaders from DuPont and Royal Dutch/Shell Group of Companies, write of the need for global partnerships between business, governments and civil society as well as the opening of opportunities for all and using markets as a mechanism for creating a more robust and just future. "The market economy, if utilized rather than worshiped, is the best mechanism available for pursuing both economic dynamism and desirable social goals," (Holiday, Schmidheiny, \& Watts, 2017).

The Sustainability Lens, as presented in the book, Social Entrepreneurship as Sustainable Development, is a tool that connects these phenomena - the explosive use of the BMC for innovation and development; the growing demand for sustainable, meaningful products, services and systems in an organization; and the desire for organizations themselves to transform into becoming more meaningful and beneficial - initiating change and providing solutions rather than creating problems (Stenn, 2017). Any enterprise can use the Sustainability Lens to reduce risk, strengthen supply chains, improve workplace conditions, build customer relations, diversify offerings and expand the bottom line.

The Sustainability Lens combines indigenous knowledge, the concept of Circles of Sustainability, solidarity economy, and permaculture into a four-quadrant tool that works with the BMC to build creative, engaging, sustainable solutions into every aspect of one's enterprise - from start-ups to seasoned industry. It highlights the supply chain, human resource function, product development, marketing and customer relations. In addition, it compliments approaches such as Lean Launchpad for innovation and Blue Ocean Canvas for value creation. Dr. Paul James, developer of the Circles of Sustainability model writes of the Sustainability Lens, "This work redefines basic concepts of sustainability and social entrepreneurship that too long have been under the sway of narrowly conceived economic mandates such as the necessity of growth...(and is) a vibrant alternative to Western ideas of living competitively" (2017).

Perhaps the most useful part of the Sustainability Lens is its ease of use and flexible options. Users can choose to either lightly improve a situation or product, or completely re-imagine an entire organization. It is up to the user how closely they wish to examine a challenge area. Based on indigenous models, nature cycles and centuries old methods of exchange, users find it intuitive and easy to follow. The Sustainability Lens, “...provides a set of important concepts in practical ways that allow those aspiring to be successful entrepreneurs as well as those already practicing socially conscious business to apply it to developing a more sustainable future," explained Dr. Ken Williams, Dean of the SIT Graduate Institute.

The purpose of this paper is to introduce and encourage the use and critical discussion of the Sustainability Lens (SL) as a practical sustainable development tool. This will be achieved via the following format: the Theoretical Foundation section will explain the theoretical background of the SL; the Development section will explain how the SL is used; the Discussion section will present gains and limitations posed by the SL and make recommendation for further applications, research and analysis.

\section{THEORETICAL FOUNDATION}

The Sustainability Lens is based on four theoretical paradigms: indigenous knowledge (IK) - as contextualized by the philosophy and practices of the Andean Quechua Suma Qamana paradigm; permaculture - a balanced, nature-based approach to conservation and growth; solidarity economy - an international movement amongst social scientists that expands and diversifies the means of exchange; and the Circles of Sustainability - a global model that quantifiably defines place-based sustainability in terms of economic, social, political and environmental impacts. The Sustainability Lens has four quadrants Health, Policy, Exchange and Resources - which relate to specific concepts from Suma Qamana and Circles of Sustainability (Fig. 1). Concepts of Solidarity Economy and Permaculture are overlaid across

parts of the Lens to create more depth and connections. First I will explain the two paradigms that make up the Lens' quadrants. Then I will explain how the overlaid paradigms complete the process. 


\section{Indigenous Knowledge (IK): Suma Qamana}

Suma Qamana (soo'mah - ka'ma-na) is a holistic Andean model of grassroots sustainable development, governance and policy (Choquehuanca, 2010). It means "living well" in the Andean language of Quechua. This is presented as an alternative to the western idea of "living better" than everyone else. Living better is a competitive, resource based, growth model where the goal is to have the most. "Living well" is based on balance and shared resources with the individual being only as good as the whole. Hernandez Navarro explains, "to live well is to think not only in terms of per capita income, but of cultural identity, community, harmony among ourselves and with Mother Earth" (2012).

Suma Qamana is based on the four quadrants or directions of the chakana or Andean Cross, a southern hemisphere constellation that, in Andean mythology, represents harmony and equilibrium with people and nature. This harmony and equilibrium transcends national and regional trade and identity barriers to recover the idea of a living world and to re-learn human life skills, impart the urgency of having cross-cultural perspectives, and continuously seek wisdom (Garcia, Lozano, Olivera, et al, 2004, p. 309). In addition to harmony, Suma Qamana and Andean philosophy is balanced by disharmony, or opposites. Opposites, it is believed, form a whole, creating a dynamic tension between both sides that together is stronger than either one (Huanacuni Mamani, 2010). Suma Qamana intentionally seeks disharmony, a system of checks and balances, to keep the whole complete. An example is the embracing of local trade and global trade together, or the use of environmentally harmful extractives such as natural gas to fund the development of sustainable energy. Both are held together and equally valued with neither being right, wrong or better than the other. In Suma Qamana, opposites make a whole and businesses intentionally seek opposites for balance.

Suma Qamana's four points in the Andean Quechua language are Munay (loving), Ruray (doing) and Ushay (power) and Yahcay (knowing). The center is Kausay (wisdom). When looking at these four points through a business lens, they bring into focus items needed for building business sustainability: Health (Munay), Policy (Ruray), Exchange (Ushay), and Resources (Yachay) (Fig. 1).

FIGURE 1

\section{THE IK PARADIGM: SUMA QAMANA AND THE SL}

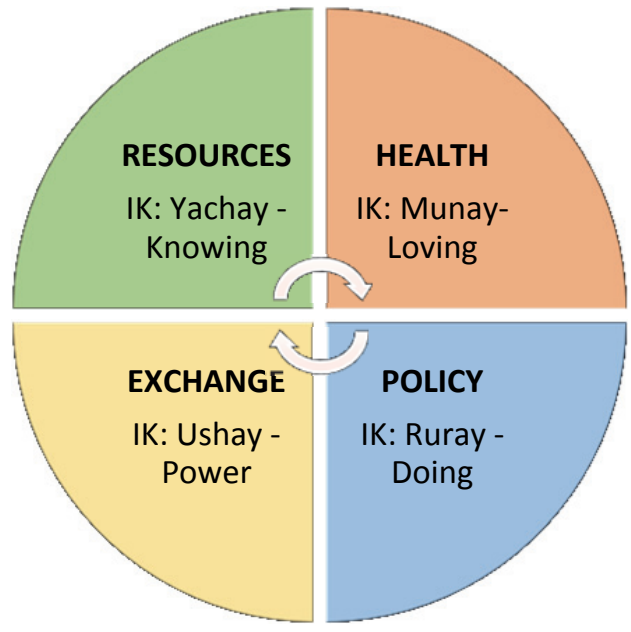

Munay is loving and the need to be passionate about something. It is in the Health quadrant and encompasses emotions, intuition, transcendence, affection, willpower, consent, affection, self-esteem, friendship, mysticism and the ability to think with the heart (Garcia, Lozano, Olivera, et al, 2004). In business models, these are often looked at as "soft skills" and left to the Human Resource Department to develop. However, Suma Qamana is a total way of being and a model that is wholly embraced both individually and organizationally (Huanacuni Mamani, 2010). In the workplace, Munay can be 
associated with volunteerism and celebration; some people call this "morale." Businesses that have strong Munay have lower turnover, higher productivity, and more fun.

Ruray is action and doing. It is in the creative Policy quadrant and the capacity to produce, build, generate, implement, experiment, develop and innovate both on a product or service level and on a personal level (Garcia, Lozano, Olivera, et al, 2004). This aspect of self-development and the vulnerability it implies is particularly important. So is the idea of experiment, because this implies that the outcomes are unknown. With the Andean embracing of opposites, Ruray can only be achieved through embracing both failure and success, as these opposites are considered necessary factors of the whole process. Being able to take the risk to imagine and act on something new or different opens the way for more creativity in the workforce, as it gives employees [participants] permission to experiment with new ideas, regardless of outcome.

Ushay is power, force, energy, vitality and also the potential and possibility for this. It is in the Exchange quadrant and represents power over one's environment and over others, for example in decision-making and authoritative capacities (Garcia, Lozano, Olivera, et al, 2004). However, Ushay is dimensional, as much of Suma Qamana is. This means that one not only exerts power, but reflects upon it. Ushay leads to action followed by dialogue and debate that welcomes contradictions.

Yachay refers to knowing and being aware of one's interrelation with the world. It is in the Resources quadrant and is about developing expertise, building skills, acquiring knowledge and embracing a diversity of worldviews and rationalities (Garcia, Lozano, Olivera, et al, 2004). Yachay happens in business, often in the areas of supply chain and natural resources management. It is knowing where products come from, how materials are made and sourced, where a business' energy comes from, and what environmental and social impacts there are in a full product lifecycle.

\section{Circles of Sustainability}

The Circles of Sustainability paradigm offers another set of quadrants which compliment those established by Suma Qamana and bring another dimension of possibility and interpretation to the Sustainability Lens. The Circles of Sustainability is a balanced way of viewing exchange as a, "process of extension and intensification of social relations across world-space, where the nature of world-space is understood in terms of the temporal frame or of the social imagery in which that space is lived - ecology, economic, politics and culture," (James, 2015, p. 28). The quadrants ecology, economy, politics and culture capture one's interconnectedness on many levels through nature, trade, society and traditions. Within Circles of Sustainability, each quadrant has a series of seven comparative items which are measured via a survey in a Sustainability Analysis, resulting in a total of 28 points of comparison (James, 2015). Circles of Sustainability builds a method of comparison over time and space and creates a common language and understanding around sustainability. This paradigm has been used in UNDP projects to define the complex dynamics of cities. When applied to the SL, it creates a conversation about sustainability using universally understood parameters, terms and goals. The Sustainability Lens takes the ideas of the Circles of Sustainability and shows how entrepreneurs can apply them to their enterprises, creating new ways in which to envision sustainable business interactions, build more inclusion, and

solidify customer relations. Applying each of the four Circles' quadrants to an entrepreneurial mindset generates new ways in which to think about enterprises' connections, roles, influences, options and choices in sustainable development. The following introduces to each quadrant and summarizes what it stands for in the SL (Fig. 2): 


\section{FIGURE 2}

\section{THE CIRCLES OF SUSTAINABILITY PARADIGM AND THE SL}

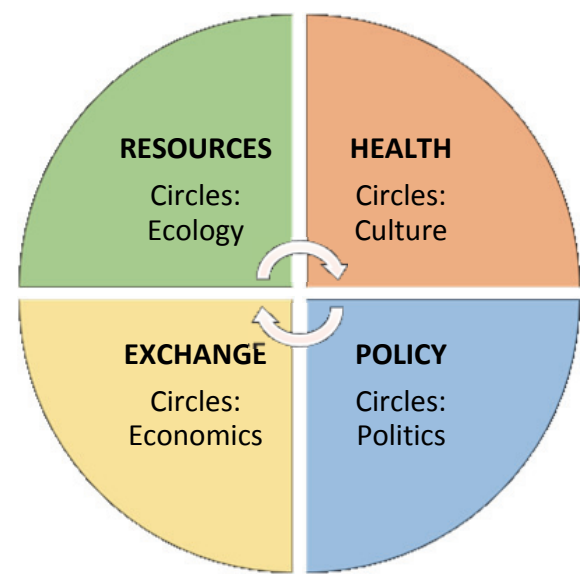

The Culture quadrant concerns practices, discourses, and material expressions, which, over time, express the continuities and discontinuities of social meaning in a life held-in-common. It goes beyond day-to-day considerations in a business and focuses more on the businesses' relationship and role in a community and society. It considers how people are able to live the lives they have reason to value, a realm deeply studied by Nobel Laureate economist, Amartya Sen. The Culture quadrant is about the people and place where a product or service is generated. It emphasizes mindful choices in practices, discourses and material expressions associated with the production, use, and management of resources. More specifically, the Culture quadrant takes into account identity, engagement, creativity, recreation, memory, projection, belief, meaning, gender, generations, inquiry, learning, well-being and health applied to a business environment (James, 2015).

The Politics quadrant focuses on practices and meanings associated with basic issues of social power as they pertain to the organization, authorization, legitimation and regulation of a social life held-incommon. This quadrant is about policy, rules and regulations both internally and externally. It highlights practices and meanings associated with basic issues of social power in relation to the organization, authority, and regulation of a common social life (James, 2015). More specifically, it encompasses organizational structure, governance, law, justice (rules and consequences), communication, critique, representation, negotiation, security, accord, dialogue, reconciliation, ethics and accountability (ibid).

The economics quadrant encompasses the practices, discourses, and material expressions associated with the production, use and management of resources. This quadrant is about resourcing, exchange, transfer, accounting, regulations, consumption, labor, welfare, technology, infrastructure, wealth and distribution (James, 2015). It emphasizes the practices, discourses and material expressions associated with such activities whether human, intellectual or material (ibid). These can appear to overlap with Politics in its nod towards regulation and also Ecology in its concern about resource use, but it differs in that it prioritizes resource valuation. Economics is often associated with scarcity and efficiency, with business leaders trying to get the greatest return with limited inputs. However, inefficiency, diversity, and abundance can also be present in Economics and lead to even more successful outcomes. By looking at consumption and exchange in a spirit of shared use, with the goal of creatively meeting the needs of all, new ways of realizing economic success and welfare arise.

The ecology quadrant is about access, transformation, and the use of materials between social and natural realms. This includes human engagement with nature ranging from the built-environment found in towns and cities to open wilderness spaces. It explores the intersection between the social and natural realms, and it includes the full spectrum of environmental conditions. More specifically, the ecology quadrant examines materials, energy, water, air, flora, fauna, habitat, settlements, structures, 
transportation, sustenance, emissions and waste (James, 2015). This is important because rarely are all of these elements together taken into consideration in traditional business environments. In this quadrant, the source of the energy, the impact of its creation and the results of its use are measured, as are the sources of all materials used in production and their impact on workers who extract and assemble them. Structures are also measured with a look at the impact of construction and maintenance on local environments and community, including animals, plants and ecosystems. In the business world, this is often known as Product Lifecycle Management (PLM). However, the Ecology quadrant goes deeper, offering a more comprehensive approach to PLM, specifically in areas of product sourcing and energy use.

\section{Solidarity Economy}

Solidarity Economy provides a veneer over two quadrants of the SL: Health and Policy. Solidarity Economy is a global approach to economics that goes beyond simple monetary exchange to value volunteerism, cooperatives, barter, community and the natural environment (Kawano, Masterson, \& Teller-Elsberg, 2005). In doing so, it builds resilience by diversifying the ways in which work gets done, builds community by forming new ways for organizations to work together, and grows abundance by creating a "giving mindset." The solidarity economy veneer looks at how an enterprise intersects with basic needs of a community, which include: education, shelter, health care, employment, food, water, and energy. It analyzes how these needs can be met through the economic cycle of creation, production, exchange, use, and the allocation of surpluses. Applying concepts of Solidarity Economy to the SL brings many creative ways in which operations can take place, products and services be delivered and materials accessed - without sole dependency on a dollar-based exchange. This strengthens organizations economically and socially while minimizing risks for entrepreneurs. Many Solidarity Economy based solutions the SL illuminates include partnering with organizations for workplace skills development such as internships for education, working with local energy companies for shared energy grid projects, or reaching out across industries to find new uses for byproducts and waste. Solidarity economy in the SL is about sharing and working with others in mutually beneficial, collaborative ways.

\section{Permaculture}

Permaculture applies to the two quadrants of the SL: Exchange and Resources, providing its own veneer as well. Permaculture is a holistic nature-based model that creates partnerships and synergy within an organization. Permaculture is about sourcing and transforming resources in a balanced, sustainable way and examining how different entities support each other though complex relationships in the natural world. This is relevant to enterprises as they strive to create value through the transformation of goods or the production of services. There are three core tenets of permaculture: care of the earth, care of people and return of surplus (Holmgren, 2001). For care of the earth, nature favors redundancy over efficiency. In redundancy, systems differ slightly from each other so if one fails, there are others that still exist and may even flourish in the absence of another. Entrepreneurial redundancy minimizes risk, expands possibilities and changes the way in which resources are accessed and consumed. The permaculture paradigm also advocates for a zero waste economy where all energy is renewable and discarded materials are designed to become resources for others to use. This paradigm maintains balance through place-based closed loop systems which in entrepreneurship terms, keeps wages local and people consuming what they produce. Surplus in enterprises can be viewed negatively. Surplus could indicate a disequilibrium or a breakdown in supply and demand. However, permaculture thrives on surplus working in abundance to take what is needed and re-invest the rest. Permaculture based organizations plan for surplus, being sure to have extra product available to give back to the community. Finding inspiration in nature's systems, new ways emerge for enterprises to interact with and transform their environment in mutually beneficial, sustainable ways. Permaculture based solutions in the SL include the re-use of resources, abundance, redundancy, the forming of partnerships and learning from nature (Fig. 3). 


\section{FIGURE 3 \\ THE SL COMPLETE - WITH ALL FOURS QUADRANTS AND PARADIGMS APPLIED}

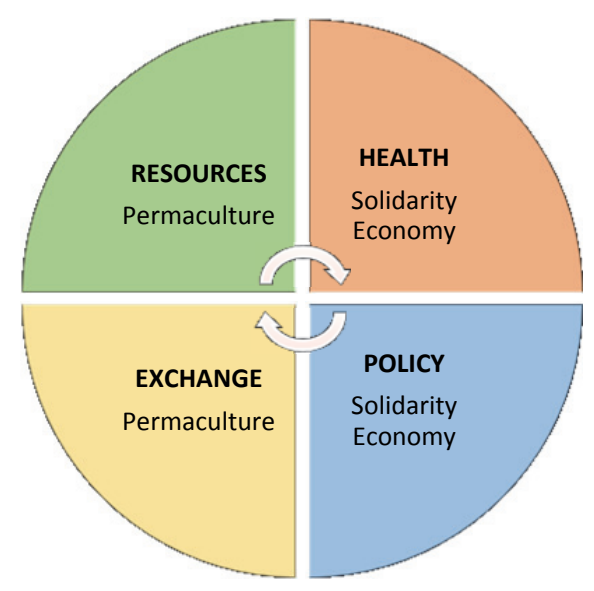

\section{DEVELOPMENT}

Like a detective using a magnifying glass to look for clues in a crime scene, the Sustainability Lens uncovers clues as to how and where more sustainability can be built into an enterprise. Think of the Sustainability Lens as a large hand-held magnifying glass with the glass divided into four quadrants: Health, Policy, Exchange, Resources. As one "holds" the Lens over the BMC and peers through the four different quadrants, new possibilities emerge in each of the nine different BMC sections. In all, 45 different points of sustainability development can be identified. The result can be transformative. What emerges is no longer a social versus economic view or one that is an $\mathrm{A}+\mathrm{B}$ approach, rather it a new synergistic rendering of both. It also becomes an active model used to facilitate change and build sustainability, not simply assess it. It involves creativity, taking the time to ask hard questions and a commitment to building innovative solutions. Some solutions may be amazingly easy, while others require slow building and implementation over time.

Once the Sustainability Lens is used, "to do" items become visible. These can be prioritized, strategized and promoted, strengthening the company's practices, products, impact, and reputation. The Sustainability Lens creates great storytelling and marketing moments, helping businesses to build their "unique selling point" and set themselves apart from the competition. The Sustainability Lens also helps businesses align more with community, thereby building a more solid client base, happier employees, and mutually beneficial partnerships.

The Sustainably Lens is best used in the context of a corporate training or retreat, with decision makers present. There are several options on how it can be used. A highly committed organization can arrange a weekend long retreat to deeply examine all 45 Sustainability Lens points, allowing approximately two hours each or assigning them to committees and then regrouping to share and integrate suggestions. An organization with less time, or wanting to take a slower approach, can break the BMC into nine different two-hour meetings, focusing on each BMC section with the Sustainability Lens. As a problem solving or innovation tool, the Sustainability Lens can be used with any single part of the BMC to achieve good results. The Sustainability Lens is that flexible. In addition, one can take a "long view" and use the Sustainability Lens to provide a single blurred view as it transits each sector. This transforms the four quadrants into a single overarching concept, thus bringing in nine additional points of sustainability and creating a "gestalt" view of one's enterprise as it goes over each sector - merging the four quadrants into a single overarching concept. This brings in 9 more points of sustainability and creates a fast, easy access "view" of one's enterprise or project. In all, the Sustainability Lens creates 54 new meaningful possibilities for engaging in sustainability. The Sustainability Lens is designed to bring into focus win-win situations that elevate the well-being of all; 
the practitioner, community, and customers. It is not meant to be imposing or punishing, rather it is meant to be illuminating and enlightening by identifying areas of positive growth, impact, and meaning.

\section{DEFINITIONS}

The following summarizes each of the four quadrants, derived from their theoretical models (Fig. 4):

\section{Resources}

Where supplies come from. Realized by actively seeking the best sources for energy, materials, and production to minimize a business' impact on eco-systems and maximize the benefits it brings to people and the planet. This includes supply chain management for self and suppliers, sourcing of raw materials down to the very from which it springs, and managing waste and the product's lifecycle through active, ongoing research and query.

\section{Health}

Impact and engagement. Realized by building love in a business through customer, contractor and employee relations, celebrations, transparency, and trust. Customers, contractors, and employees are democratically engaged in decision making and strategizing. The organization strives to ensure that customers, contractors, employees and members of their communities are able to live the life they have reason to value by seeking ways the organization can help to build opportunities and capabilities.

\section{Policy}

Advocacy and influence. Realized by actively modeling and advocating for changes needed for greater Sustainability through internal business policies and external influences. These include the supplier selection, production methods, profit and investment, and community engagement. Here organizations can participate in dialogue and be open to different ideas.

\section{Exchange}

Accessibility and distribution. Realized by an organization seeking to diversify methods of exchange through barter, volunteerism, the use of a cooperative ownership structure, profit sharing, local currencies, time trades and closed loop lending. Organizations monitor the speed and pace of their business to ensure that exchanges are more equal and growth is steady. 
FIGURE 4

THE FOUR QUADRANTS OF THE SUSTAINABILITY LENS SUMMARIZED

\begin{tabular}{|c|c|}
\hline $\begin{array}{l}\text { RESOURCES } \\
\text { Where supplies come from } \\
\text { Supply Chain Management: } \\
\text { - Trace inputs down to the very soil } \\
\text { they originate from. } \\
\text { - Recognize all hands that touch it. } \\
\text { - Recognize community impacted. } \\
\text { - Recognize energy used. } \\
\text { Note: Requires full transparency from } \\
\text { suppliers. }\end{array}$ & $\begin{array}{l}\text { HEALTH } \\
\text { Human engagement and community } \\
\text { Participatory Democracy: } \\
\text { - Build a collaborative community } \\
\text { - Democratically engage stakeholders } \\
\text { (customer, contractor, and employee) } \\
\text { in decision making, risk taking, and } \\
\text { strategy wherever possible. } \\
\text { - Seek ways to collectively build } \\
\text { opportunities, inclusion and } \\
\text { celebration. }\end{array}$ \\
\hline \begin{tabular}{l}
\multicolumn{1}{c}{ EXCHANGE } \\
Accessibility and distribution \\
Accessibility: \\
- Diversify methods of exchange \\
through barter, volunteerism, \\
cooperatives, profit sharing, local \\
currencies, time trades and/or closed \\
loop lending. \\
- Slow down. \\
- Find a pace that positively aligns with \\
available resources and labor.
\end{tabular} & $\begin{array}{l}\text { POLICY } \\
\text { Set the example. Be the change. } \\
\text { Engagement: } \\
\text { - Actively model and advocate for } \\
\text { greater Sustainability through internal } \\
\text { business policies and standards. } \\
\text { - Extend these standards externally } \\
\text { requiring suppliers to follow them. } \\
\text { - Invite customers to embrace them. } \\
\text { - Encourage community involvement. } \\
\text { - Participate in dialogue and be open to } \\
\text { different ideas. }\end{array}$ \\
\hline
\end{tabular}

\section{DISCUSSION}

The Sustainability Lens is just the beginning. It was developed as a way to start a conversation and look in new ways at the power that businesses have to affect meaningful change, set examples (be the change), and lead the way to a more equitable, just and healthy future for all. There are many organizations working towards sustainable solutions to the challenges in our world. Certified Fair Trade organizations protect workers' rights and build market access for disadvantaged producers, certified B Corps promote social and environmental responsibility, organic certifications make sure products are made without artificial methods, and there are many more. There are various, non-certified, ways in which to achieve sustainability and many paths to take. This is just one.

Based on indigenous knowledge that shaped our relations with the earth and each other before industrialization, globalization and rapid change, and cycles of nature which exist around us every day, I hope this model resonates, makes sense and can be put to the test. I challenge readers to question and use it - with a critical eye. I am interested in knowing how to improve it. How this model can be simplified in its language to be even more intuitive - without losing its meaning. What works and what does not. And how it can be more accessible and used by all. Sustainability is an aspiration, not a destination, and one that is dependent on all of us to achieve. The more tools we have to better understand what Sustainability is and how we can be a part of growing it, the better for all. 


\section{CONCLUSION}

The Sustainability Lens is constructed with decades of real-life experience in building social enterprises from Washington, DC's first eco-friendly advertising agency in the 1980s to a global FairTrade hand knit alpaca clothing company with production in Bolivia. It is also based on years of academic research into sustainability, leadership, and indigenous ways of being. Examples of the benefits received when using Sustainability Lens principles abounds, from energy regeneration of Fat Tire Brewing, to participatory tourism of Runa Tea, to Patagonia's environmental commitments. The challenge is now for others to test the Sustainability Lens for themselves. In a workshop, corporate imitative, case study, or start-up, the tool is free, accessible and available. I challenge practitioners to make it stronger and academics to create more literature around it. As indigenous scholars say, sustainability only exists as far as the next neighbor. If a neighbor is suffering and not accessing needed resources or fails to regenerate or cooperate, then it affects us all. Like concentric circles extending across a pond's surface, our actions touch those of others. It is only through unity in commitment that we can achieve a more healthy, balanced, sustainable way of being.

\section{REFERENCES}

Amarsy, T. (2015, February 9). Why and how organizations around the world apply the Business Model Canvas. Strategyzer. Retrieved from https://blog.strategyzer.com/posts/2015/2/9/why-and-howorganizations-around-the-world-apply-the-business-model-canvas

Choquehuanca, D. (2010). Vivir Bien. Ministry of Foreign Relations. Bolivia.

Cohen, S. (2014, December 29). The growing level of environmental awareness. The Huffington Post. Retrieved from https://www.huffingtonpost.com/steven-cohen/the-growing-level-ofenvi_b_6390054.html

Garcia, J., Lozano, A., Olivera, J., \& Ruiz, C. (2004). Sumak yachaypi, alli kawsaypipash yachakuna= Aprender en la sabiduría y el buen vivir = Learning wisdom and the good way to live. Quito, Ecuador: Amawtay Wasi Cross Cultural University.

Hernandez Navarro, L. (2012, 12 March). Bolivia has transformed itself by ignoring the Washington Consensus. The Guardian. Retrieved from https://www.theguardian.com/commentisfree/cifamerica/2012/mar/21/bolivia-washingtonconsensus

Holliday, J., Schmidheiny, S. \& Watts, P. (2017). Walking the talk: The business case for sustainable development. New York: Routledge.

Holmgren, David (2017). Permaculture: Principles \& pathways beyond sustainability (Rev. ed.). Hepburn, Victoria: Melliodora Publishing.

Huanacuni Mamani, F. (2010). Vivir bien/buen vivir (4th ed.) Lima, Peru: Coordinadora Andina de Organizaciones Indigenas (CAOI).

James, P. (2015). Urban sustainability in theory and practice: Circles of sustainability. London: Routledge.

Kawano, E., Masterson, T. \& Teller-Elsberg, J. (2009). Social solidarity economy: Building alternatives for people and planet: Papers and reports from the 2009 forum on the solidarity economy. Amherst, MA: Center for Popular Economics.

Stenn, T. (2017). Social entrepreneurship as sustainable development. New York: Palgrave. 


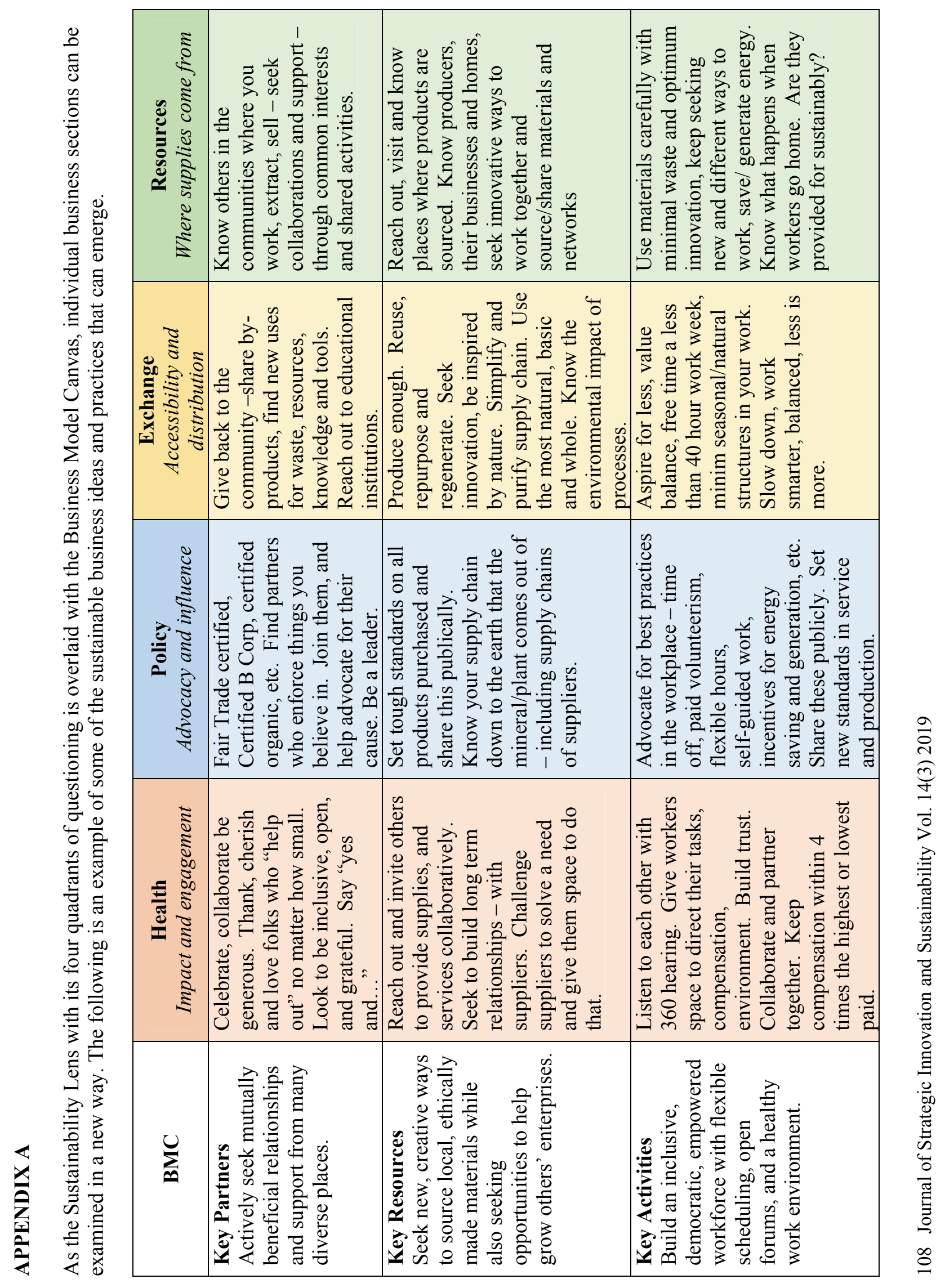




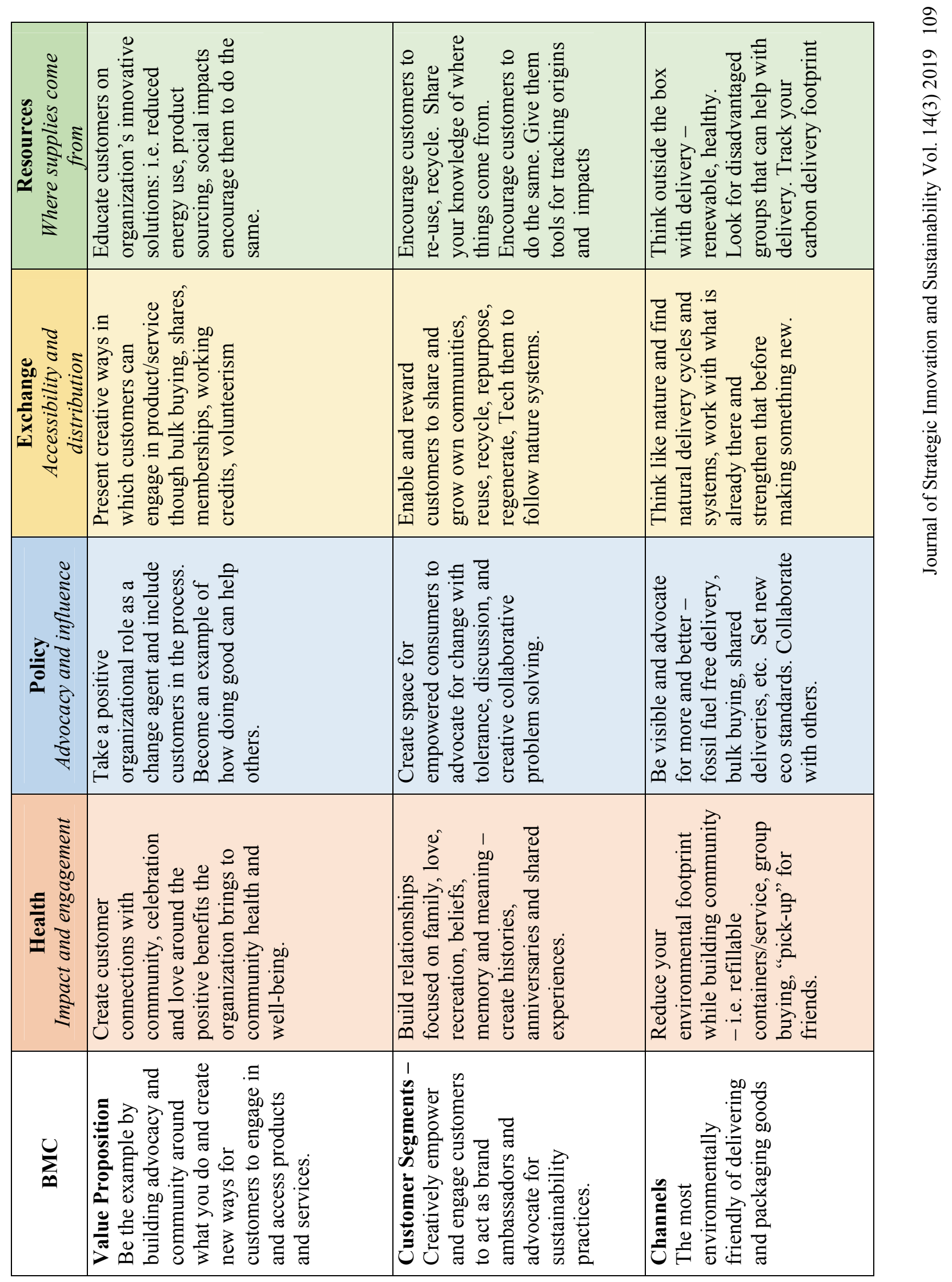




\begin{tabular}{|c|c|c|c|}
\hline 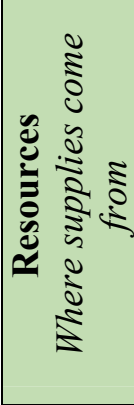 & 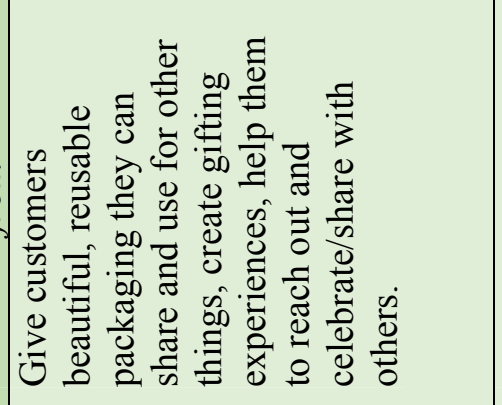 & 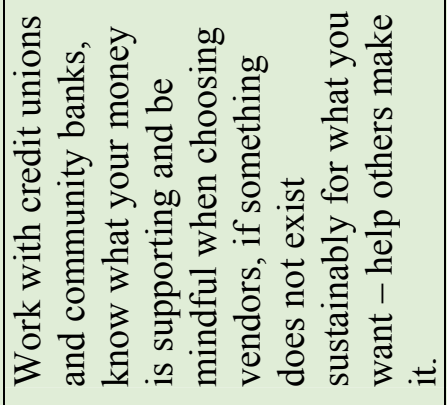 & 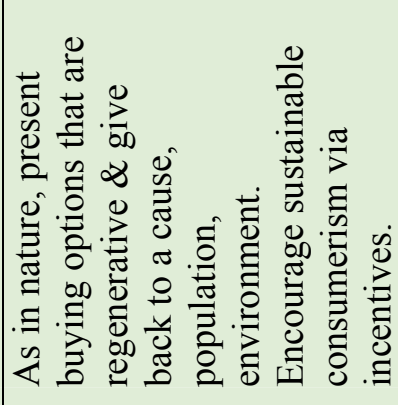 \\
\hline 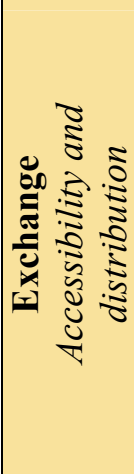 & 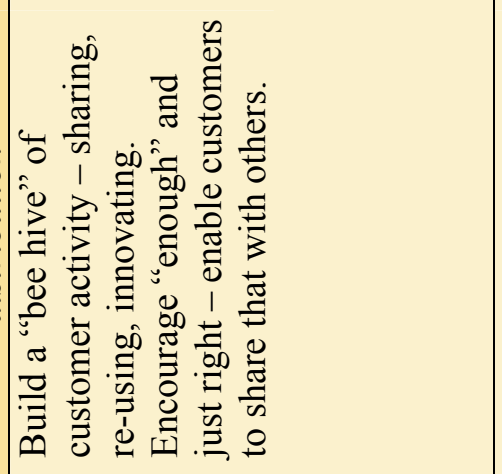 & 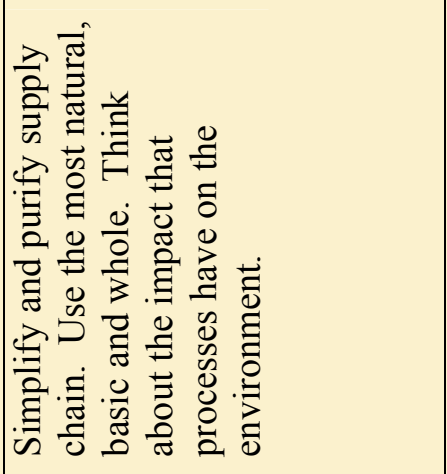 & 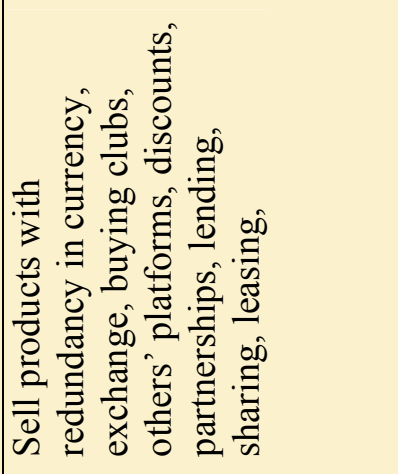 \\
\hline 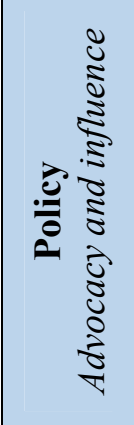 & 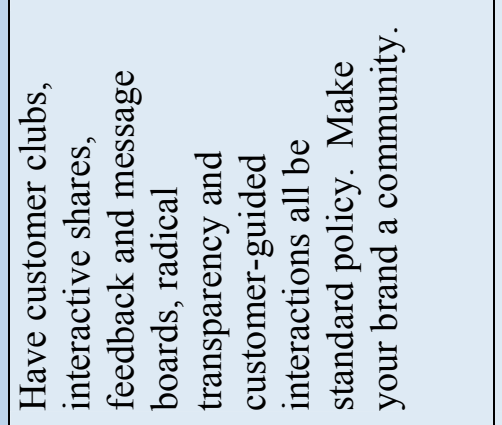 & 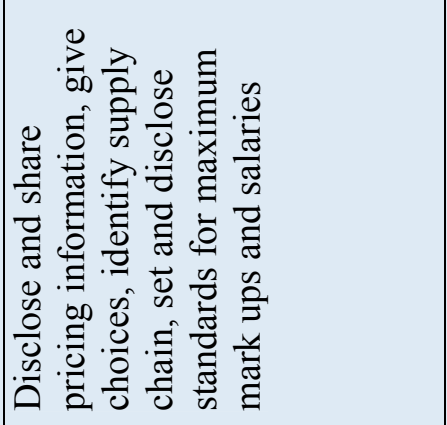 & 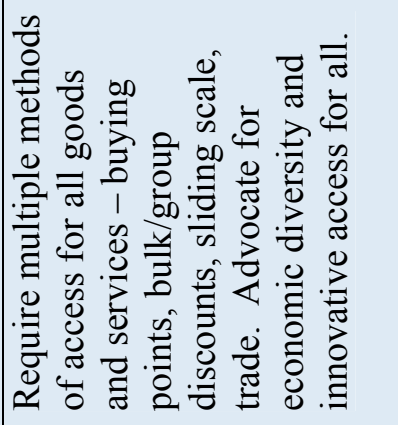 \\
\hline 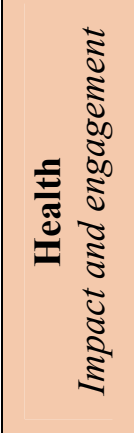 & 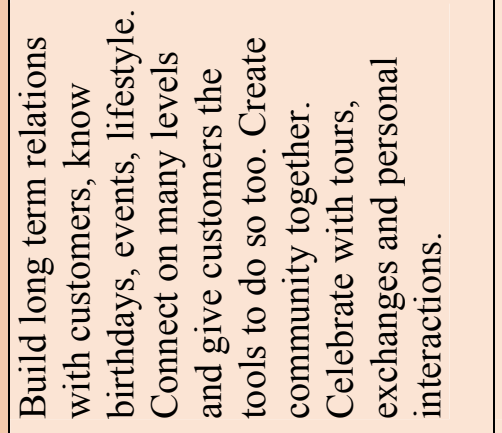 & 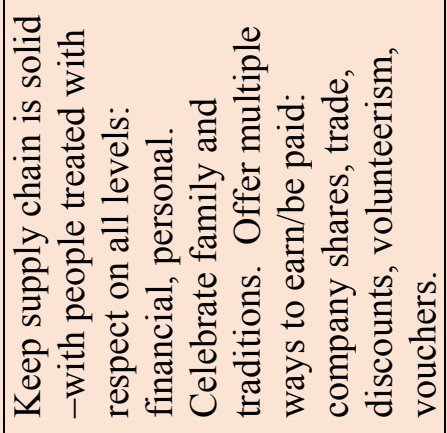 & 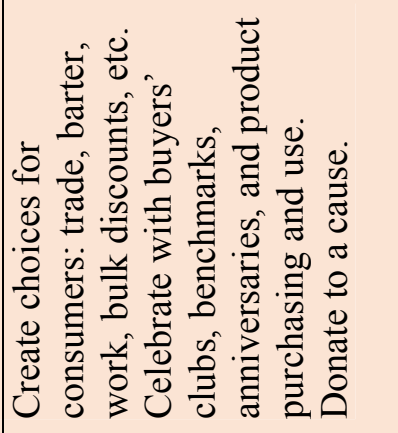 \\
\hline$\sum_{\infty}^{U}$ & 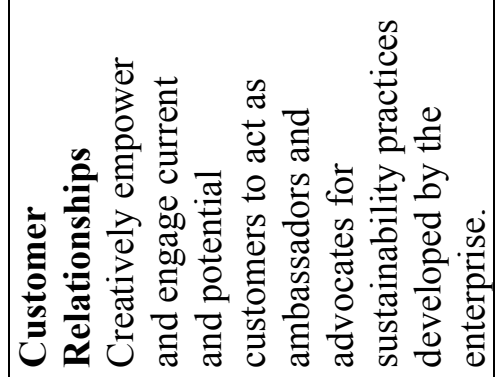 & 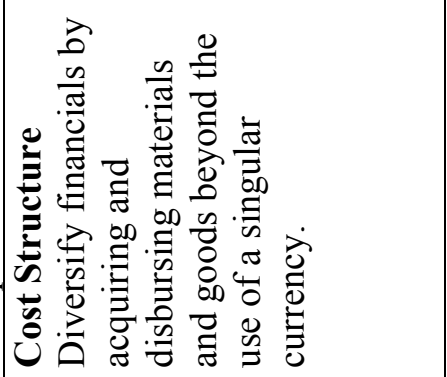 & 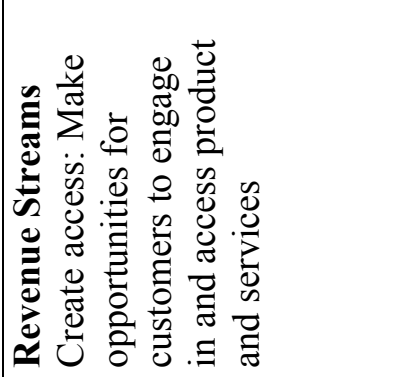 \\
\hline
\end{tabular}

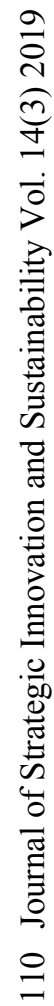

